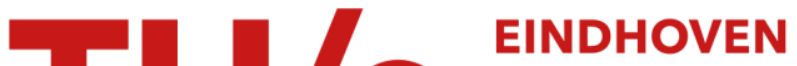 UNIVERSITY OF TECHNOLOGY
}

\section{Fragmentation of organic ions bearing fixed multiple charges observed in MALDI MS}

\section{Citation for published version (APA):}

Lou, X., Li, B., de Waal, B. F. M., Schill, J., Baker, M. B., Bovee, R. A. A., van Dongen, J. L. J., Milroy, L. G., \& Meijer, E. W. (2018). Fragmentation of organic ions bearing fixed multiple charges observed in MALDI MS. Journal of Mass Spectrometry, 53(1), 39-47. https://doi.org/10.1002/jms.4035

DOI:

10.1002/jms.4035

Document status and date:

Published: 01/01/2018

\section{Document Version:}

Publisher's PDF, also known as Version of Record (includes final page, issue and volume numbers)

\section{Please check the document version of this publication:}

- A submitted manuscript is the version of the article upon submission and before peer-review. There can be important differences between the submitted version and the official published version of record. People interested in the research are advised to contact the author for the final version of the publication, or visit the $\mathrm{DOI}$ to the publisher's website.

- The final author version and the galley proof are versions of the publication after peer review.

- The final published version features the final layout of the paper including the volume, issue and page numbers.

Link to publication

\section{General rights}

Copyright and moral rights for the publications made accessible in the public portal are retained by the authors and/or other copyright owners and it is a condition of accessing publications that users recognise and abide by the legal requirements associated with these rights.

- Users may download and print one copy of any publication from the public portal for the purpose of private study or research.

- You may not further distribute the material or use it for any profit-making activity or commercial gain

- You may freely distribute the URL identifying the publication in the public portal.

If the publication is distributed under the terms of Article 25fa of the Dutch Copyright Act, indicated by the "Taverne" license above, please follow below link for the End User Agreement:

www.tue.nl/taverne

Take down policy

If you believe that this document breaches copyright please contact us at:

openaccess@tue.nl

providing details and we will investigate your claim. 


\title{
Fragmentation of organic ions bearing fixed multiple charges observed in MALDI MS
}

\author{
Xianwen Lou ${ }^{1}$ (I) $\mid$ Bao Li $^{1}$ | Bas F.M. de Waal ${ }^{1}$ | Jurgen Schill ${ }^{2}$ | Matthew B. Baker ${ }^{1}$ | \\ Ralf A.A. Bovee ${ }^{1}$ | Joost L.J. van Dongen ${ }^{1}$ | Lech-Gustav Milroy ${ }^{2,3}$ । E.W. Meijer ${ }^{1,3}$
}

\author{
${ }^{1}$ Laboratory of Macromolecular and Organic \\ Chemistry, Eindhoven University of \\ Technology, P.O. Box 513, $5600 \mathrm{MB}$ \\ Eindhoven, The Netherlands \\ ${ }^{2}$ Laboratory of Chemical Biology, Department \\ of Biomedical Engineering, Eindhoven \\ University of Technology, P.O. Box 513, 5600 \\ MB Eindhoven, The Netherlands \\ ${ }^{3}$ Institute of Complex Molecular Systems \\ (ICMS), Eindhoven University of Technology, \\ P.O. Box 513, 5600 MB Eindhoven, The \\ Netherlands

\section{Correspondence} \\ Xianwen Lou, Laboratory of Macromolecular \\ and Organic Chemistry, Eindhoven University \\ of Technology, P.O. Box 513, 5600 MB \\ Eindhoven, The Netherlands. \\ Email: x.w.lou@tue.nl
}

\begin{abstract}
Matrix-assisted laser desorption/ionization time-of-flight mass spectrometry (MALDI TOF MS) was used to analyze a series of synthetic organic ions bearing fixed multiple charges. Despite the multiple intrinsic charges, only singly charged ions were recorded in each case. In addition to the pseudo-molecular ions formed by counterion adduction, deprotonation and electron capture, a number of fragment ions were also observed. Charge splitting by fragmentation was found to be a viable route for charge reduction leading to the formation of the observed singly charged fragment ions. Unlike multivalent metal ions, organic ions can rearrange and/or fragment during charge reduction. This fragmentation process will evidently complicate the interpretation of the MALDI MS spectrum. Because MALDI MS is usually considered as a soft ionization technique, the fragment ion peaks can easily be erroneously interpreted as impurities. Therefore, the awareness and understanding of the underlying MALDI-induced fragmentation pathways is essential for a proper interpretation of the corresponding mass spectra. Due to the fragment ions generated during charge reduction, special care should be taken in the MALDI MS analysis of multiply charged ions. In this work, the possible mechanisms by which the organic ions bearing fixed multiple charges fragment are investigated. With an improved understanding of the fragmentation mechanisms, MALDI TOF MS should still be a useful technique for the characterization of organic ions with fixed multiple charges.
\end{abstract}

\section{KEYWORDS}

artificial impurities, false interpretation, fixed multiple charges, ion fragmentation, matrix-assisted laser desorption/ionization time-of-flight mass spectrometry

\section{1 | INTRODUCTION}

Matrix-assisted laser desorption/ionization mass spectrometry (MALDI MS) is a powerful and indispensable technique for the analysis of various biological and synthetic compounds. ${ }^{1-3}$ An important characteristic of MALDI is that analytes, with the exception of very high molecular weight molecules such as proteins, are predominantly recorded as singly charged ions. ${ }^{4,5}$ This feature facilitates interpretation of the resulting mass spectra. The uncomplicated spectra together with many other advantages, including relatively straightforward operation, high sensitivity, tolerance to contamination, and rapid analysis to provide absolute molecular mass, have also rendered MALDI MS a popular analytical technique for the characterization of nonvolatile synthetic organic compounds in many chemistry laboratories across the world.
Although singly charged ions are usually the most prominent species recorded for small molecules in MALDI MS, analytes can be multiply charged in a sample solution and this original charge state might be preserved in the sample spot after the sample is dried on a MALDI target plate. ${ }^{6}$ However, highly charged molecular ions can only be observed under special conditions. ${ }^{7-10}$ Upon laser irradiation, a series of events or reactions are initiated, which lead to the observed singly charged ions. ${ }^{4,5,11-16}$ According to Karas et al, ${ }^{4,5}$ singly charged ions are the "lucky survivors" in MALDI MS. Depending on the properties of the analyte and the matrix, a number of gas phase processes are responsible for the formation of singly charged ions. For analytes such as proteins/peptides that carry more than one basic group, multiply protonated ions accompanied by counter anions will be incorporated in typically acidic matrices. Proton neutralization within matrix clusters 
or proton transfer reactions in the MALDI plume can effectively reduce the multiply charged protonated ions to singly charged ions. $^{4,5,12,13}$ Interestingly, even for complexes with multivalent metal ions, singly charged ions are still the dominant species in MALDI MS. When multivalent metal ions are added as cation reagents in the MALDI MS analysis of synthetic apolar polymers like polystyrene, the multivalent ions will be reduced to singly charged ions by catching free electrons or by gas phase charge exchange with matrix molecules. ${ }^{17,18}$ For polar synthetic polymers, on the other hand, the singly charged quasi-molecular ions can also be formed by deprotonation (eg, [analyte + metal $\left.\left.^{2+}-\mathrm{H}^{+}\right]^{+}\right){ }^{19,20}$ Schäfer and Budzikiewicz reported that deprotonation reactions and one-electron reduction are the predominant paths of transforming preformed doubly charged porphyrins to singly charged ions. ${ }^{21}$ Besides the deprotonation and electron capture reactions, another important route for charge reduction in MALDI is the attachment of counterions and/or deprotonated matrix ions. ${ }^{5,22}$

In all the examples cited above, it could be argued that the ions recorded can still be considered as (pseudo)-molecular ions because no fragmentation or rearrangement of the molecular structure occurred. The resulted MALDI MS spectra are still easy to interpret. Charge reduction in these examples is fulfilled by deprotonation, electron capture, and/or counterion attachment.

In this contribution, we report that the situation of forming singly charged ions can be more complicated for organic ions bearing fixed multiple charges. For such multiply charged ions, fragmentation into a series of singly charged ions can also be a viable route in addition to the charge reduction reactions mentioned above. Furthermore, organic ions might concurrently fragment and/or rearrange after catching electrons, which is in clear contrast with the reduction of multivalent metal ions. Obviously, these reactions can give extra fragment peaks and thus significantly complicate the interpretation of the final MALDI mass spectra. As MALDI is usually considered as a soft ionization technique, the fragments might easily be falsely interpreted as impurities. With the widespread application of MALDI MS, it can be envisaged that many new types of multiply charged organic ions will be analyzed using this technique. Therefore, it is extremely important for analysts to be aware of the possible fragmentation in the MALDI MS analysis of organic ions with fixed multiple charges.

Four types of ionic organic compounds bearing fixed positive multiple charges were studied in this work, namely, a doubly charged poly(propylene imine) diaminobutane dendrimer, ${ }^{23}$ a doubly and a quadruply charged viologen derivatives, a doubly and a triply charged benzene-1,3,5-tricarboxamide derivatives, ${ }^{24,25}$ and a doubly charged perylene derivative (Figure 1). The results clearly indicate that fragmentation and rearrangement reactions can occur in the charge reduction of multiply charged organic ions in MALDI MS. Possible mechanisms for fragmentation and rearrangement of these compounds were investigated. The aim of this contribution is to stress that an awareness of possible fragmentation and the understanding of the fragmentation mechanisms are essential for proper interpretation of the mass spectra in the MALDI MS analysis of organic ions bearing fixed multiple charges.

\section{2 | EXPERIMENTAL}

The structures of all the analytes studied are given in Figure 1. The syntheses of QDendr1 and the 2 benzene-1,3,5-tricarboxamide (BTA) derivatives have been reported in previous publications by our group. ${ }^{23-25}$ Syntheses and nuclear magnetic resonance characterization of the 2 viologen derivatives and the perylene derivative are provided in the electronic supplement information (ESI).

Three matrices were used in this work. a-Cyano-4hydrocycinnamic acid (CHCA) and tetrathiafulvalene (TTF) were purchased from Fluka (Zwijndrecht, The Netherlands), and 2-[(2E)-3(4-tert-butylphenyl)-2-methylprop-2-enylidene] malononitril (DCTB)

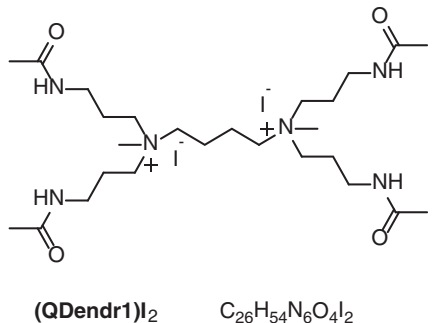

(1)
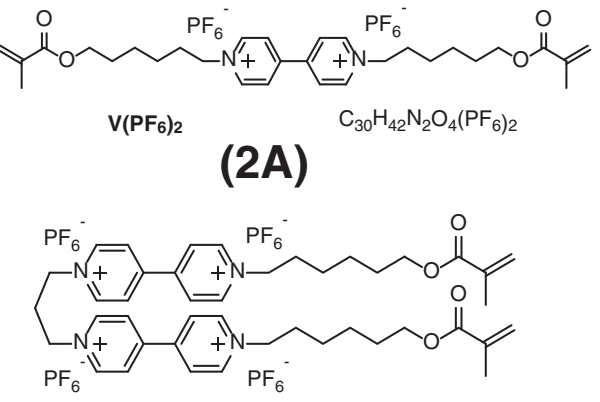

$\mathrm{BV}\left(\mathrm{PF}_{6}\right)_{4}$

$\mathrm{C}_{43} \mathrm{H}_{56} \mathrm{~N}_{4} \mathrm{O}_{4}\left(\mathrm{PF}_{6}\right)_{4}$

(2B)

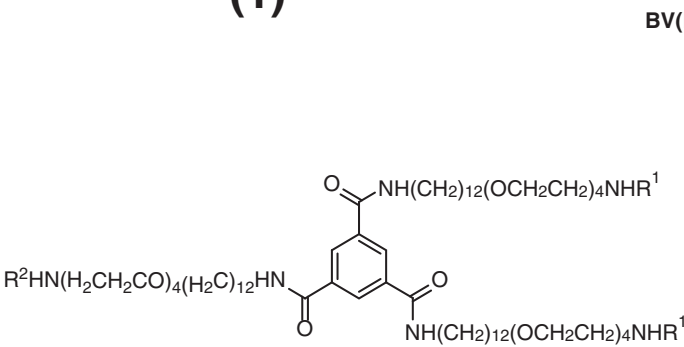

(BTA2Cy5) $\mathrm{Cl}_{2}$

$\mathrm{C}_{133} \mathrm{H}_{206} \mathrm{~N}_{10} \mathrm{O}_{17} \mathrm{Cl}_{2}$

(3A)

(BTA3Сy5) $\mathrm{Cl}_{3}$

(3B)

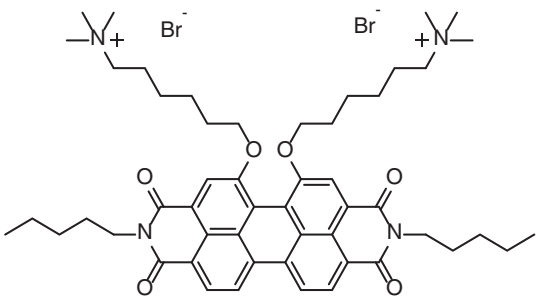

(4)

$\mathrm{C}_{52} \mathrm{H}_{70} \mathrm{~N}_{4} \mathrm{O}_{6} \mathrm{Br}_{2}$
(QPB)Br2

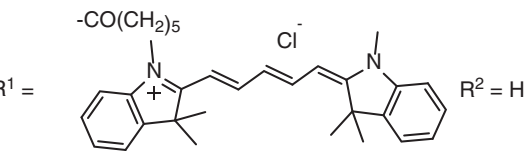

$-\mathrm{CO}\left(\mathrm{CH}_{2}\right)_{5}$

$R^{1} \& R^{2}$

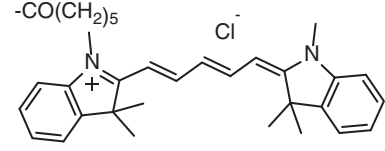

FIGURE 1 Molecular structures of the analytes investigated in this present work 
was synthesized according to Ulmer et al. ${ }^{26}$ Tetrahydrofuran (THF, analytical reagent grade stabilized with butylated hydroxytoluene) was obtained from Biosolve (Biosolve BV, Valkenswaard, The Netherlands).

Matrix solutions were freshly prepared in THF at a concentration of approximately $20 \mathrm{mg} / \mathrm{mL}$. All the sample solutions were also freshly prepared. Two percent $(\mathrm{v} / \mathrm{v})$ of water in THF was required to dissolve QDenr1, 4\% ( $/ / v)$ of water in THF to dissolve $\mathrm{V}\left(\mathrm{PF}_{6}\right)_{2}$ and $\mathrm{BV}\left(\mathrm{PF}_{6}\right)_{4}$, and $2 \%(\mathrm{v} / \mathrm{v})$ dimethyl sulfoxide (DMSO) in THF to dissolve QPB. $\mathrm{BTA} 2 \mathrm{Cy} 5 \mathrm{Cl}_{2}$ and $\mathrm{BTA} 3 \mathrm{Cy} 5 \mathrm{Cl}_{3}$ were dissolved in methanol. A sample solution and a matrix solution were mixed in an Eppendorf tube. All mass spectra shown in this article were recorded with an analyte/ matrix mole ratio of 1:100 since no considerable difference in the MALDI MS spectra concerning the fragmentation patterns was observed with the analyte/matrix mole ratios from 1:20 to 1:1000. A total of $0.5 \mu \mathrm{L}$ of the mixed solution was pipetted onto a stainless steel MALDI target plate and allowed to dry.

The matrix-assisted laser desorption/ionization time-of-flight mass spectrometry (MALDI TOF MS) measurements were performed with an Autoflex Speed (Bruker, Bremen, Germany) instrument equipped with a 355-nm Nd:YAG smartbeam laser with maximum repetition rate of $1000 \mathrm{~Hz}$, capable of executing both linear and reflector modes. The accelerating voltage was held at $19 \mathrm{kV}$ and the delay time at 130 nanoseconds for all experiments. Mass spectra were acquired in the reflector positive ion mode by summing spectra from 500 random laser shots at an acquisition rate of $100 \mathrm{~Hz}$. The MS spectra were calibrated with Csl clusters of known masses. ${ }^{27}$

\section{3 | RESULTS AND DISCUSSION}

\section{1 | Quaternized dendrimer}

Dendrimers are highly branched globular molecules, which emanate from a central core. Dendrimers have attracted significant scientific interest owing to their distinctive molecular structure. In our laboratory, a large number of poly(propylene imine) dendrimers were synthesized, and MS has been found to be a powerful tool for the analysis of these dendrimers. ${ }^{28,29}$ In this study, a first generation quaternized dendrimer (QDendr1, Figure 1) consisting of a doubly charged ion with 2 quaternized nitrogen atoms at the core and iodide as the counter ion was measured by MALDI TOF MS.

In the MALDI TOF MS measurements, DCTB is not a good matrix for Qdendr1 because it could not yield clear analyte ions. Figure 2 shows the MALDI TOF MS spectrum of Qdendr1 using CHCA. In addition to the pseudo-molecular ions of [Qdendr1 $\left.{ }^{2+}+\left(\mathrm{CHCA}-\mathrm{H}^{+}\right)\right]^{+}$and [Qdendr $\left.1^{2+}+\mathrm{I}^{-}\right]^{+}$, a number of extra peaks with much higher intensities than those of the pseudo-molecular ions were observed. Although the intact Qdendr1 ion is doubly charged, all the ions recorded in this figure are singly charged. It is known that one possible mechanism for charge reduction is through the association of counter ions as $\left[\text { Qdendr1 }{ }^{2+}+\left(\mathrm{CHCA}-\mathrm{H}^{+}\right)\right]^{+}$and $\left[\text {Qdendr1 }{ }^{2+}+\mathrm{I}^{-}\right]^{+}$, which were indeed observed in Figure 2. No [Qdendr $\left.1^{2+}-\mathrm{H}^{+}\right]^{+}$ions were observed presumably because Qdendr1 does not contain labile protons which can easily be released. Furthermore, Qdendr $1^{2+}$ cannot be reduced by

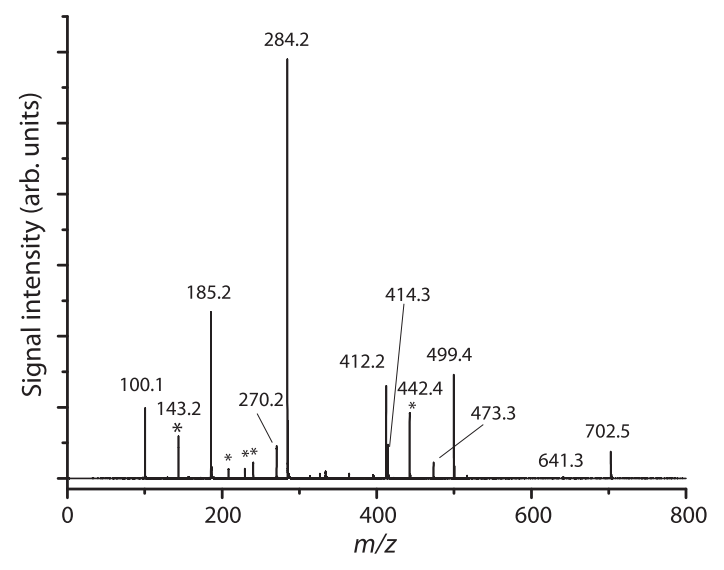

FIGURE 2 The matrix-assisted laser desorption/ionization time-offlight mass spectrometry of QDendr $1 \mathrm{I}_{2}$ using a-cyano-4-

hydrocycinnamic acid (CHCA) as the matrix. The molecular structure of the analyte is shown in Figure 1 (QDendr $1^{2+}=\mathrm{C}_{26} \mathrm{H}_{54} \mathrm{~N}_{6} \mathrm{O}_{4}{ }^{2+}$ ). The assignment of the peaks can be found in Scheme 1 and Table S1, * indicates unidentified peaks. CHCA is dissolved in THF and the analyte in THF with $2 \%$ of water. The mole ratio of analyte/CHCA is $1: 100$

simply catching one electron in the same way as multivalent metal ions, and hence no [Qdendr $\left.1^{2+}+\mathrm{e}\right]^{+}$was recorded either. Although no $\left[Q D e n d r 1^{2+}+e\right]^{+}$was observed, it will be shown below that singly charged molecular ions formed on electron capture were recorded for analytes if the molecular ions could be sufficiently stabilized via $\pi-\pi$ conjugation which is lacking for QDendr1. Based on the above reasoning and the $\mathrm{m} / \mathrm{z}$ values of the extra peaks, we propose that the corresponding ions were formed through charge loss via fragmentation.

Considering the molecular structure of Qdendr $1^{2+}$, fragmentation is expected to occur around the 2 charged $\mathrm{N}$-atoms in the core. Each charged $\mathrm{N}$-atom forms $4 \mathrm{~N}-\mathrm{C}$ bonds, 2 of which carry identical substituent groups (Figure 1). Hence, 3 hypothetical cleavage mechanisms are envisaged (see Scheme 1). In routes 1 and 2, a doubly charged ion is split into 2 singly charged ions. In route 3 , the cleavage first yields another doubly charged fragment which is further reduced to singly charged ions by charge-charge association with an anion, cleavage of one of the $\mathrm{N}-\mathrm{C}$ bonds, or by losing either a single $\mathrm{H}^{+}$or $\mathrm{CH}_{3}{ }^{+}$fragment. The molecular formula and molecular weights of the possible fragment ions predicted according to the routes shown in Scheme 1 are listed in Table S1 of the ESI. Convincingly, all the expected fragment ions, except $\mathrm{H}^{+}$and $\mathrm{CH}_{3}{ }^{+}$which might be too small to be detected in our system, could easily be found in Figure 2.

The excellent matching between the ions recorded in Figure 2 and the expected ions based on Scheme 1 strongly supports the fragmentation routes of Scheme 1. Although we could not detect $\left[\text { Qdendr } 1^{2+}+e\right]^{+}$ions, we do not rule out the possibility of charge reduction by electron capture and subsequent fragmentation. In the analysis of proteins and peptides, multiply charged ions can be fragmented by electron capture dissociation (ECD) leading to $z$ and $c$ ions. $^{30}$ It might also be possible that the recombination energy between QDendr $1^{2+}$ and electron would be redistributed throughout the reduced product to induce fragmentation. Therefore, it is very well possible that both ECD and fragmentation via charge splitting are important routes for the formation of the Qdendr1 fragment ions. 

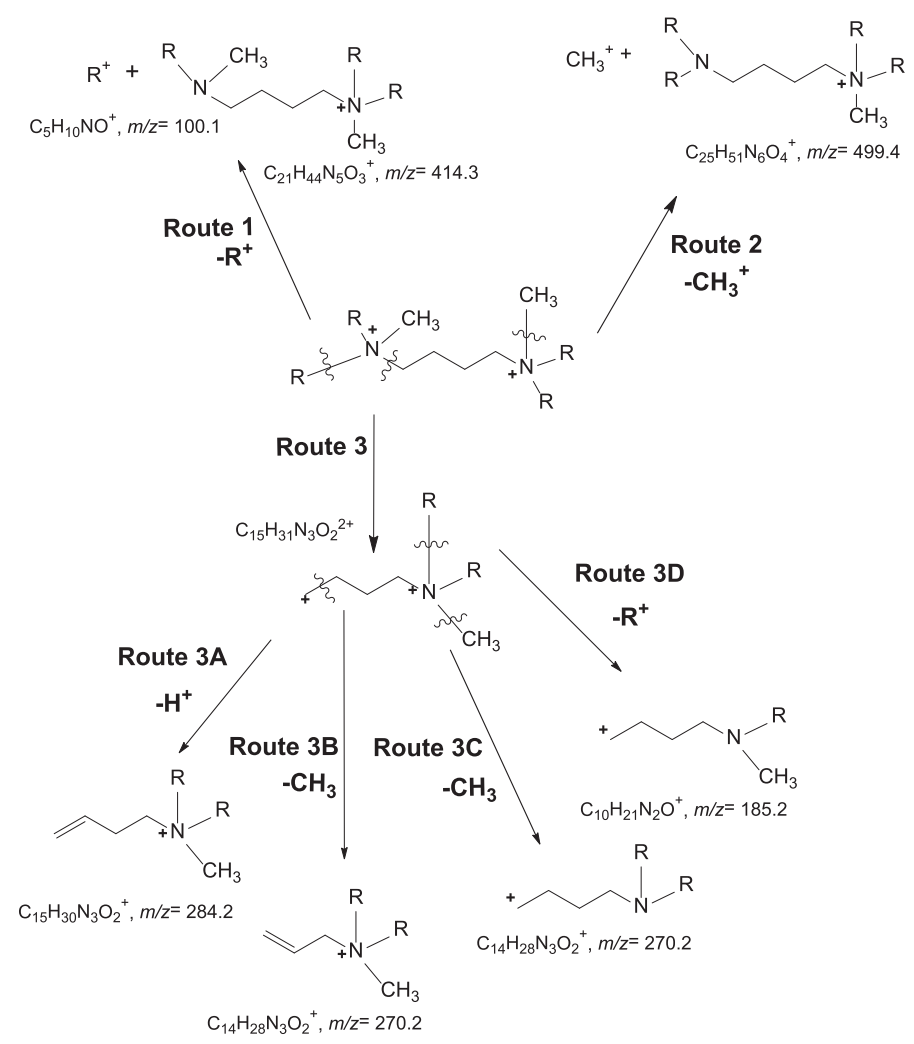

SCHEME 1 Schemes for the fragmentation of QDendr $1^{2+}$

Based on the discussion above, it is evident that Qdendr $1^{2+}$ could generate a number of fragment ions in MALDI. The fragmentation of Qdendr $1^{2+}$ is not unexpected because of the small molecular size and the lack of easily cleavable protons. The driving force for the fragmentation is the tendency to form singly charged ions in MALDI. Because of the fragmentation, additional care should be taken for the interpretation of the MALDI mass spectra for which a good understanding of the fragmentation pathways as illustrated in Scheme 1 is vital.

\section{2 | Viologen derivatives}

Viologens are bipyridiunm derivatives of 4,4'-bipyridyl which are widely used for electrochromic systems because of their ability to reversibly change color under redox conditions. In addition, there are significant recent interests in the synthesis and application of viologen derivatives in supramolecular chemistry and material science. ${ }^{31,32}$ In this work, 2 viologen derivatives were studied and their structures are shown in Figure 1. $\mathrm{V}\left(\mathrm{PF}_{6}\right)_{2}$ consists of one dicationic core of viologen, while $\mathrm{BV}\left(\mathrm{PF}_{6}\right)_{4}$ consists of 2 dicationic cores.

Figure 3 shows a MALDI TOF MS spectrum of $\mathrm{V}\left(\mathrm{PF}_{6}\right)_{2}$ using DCTB as the matrix. With DCTB, major signals of singly charged ions corresponding to $\mathrm{V}^{2+}$ with and without a single $\mathrm{PF}_{6}{ }^{-}$counter ion were recorded. By contrast, no $\left[\mathrm{V}^{2+}+\mathrm{PF}_{6}^{-}\right]^{+}$ions were detected using CHCA as matrix (see ESI, Figure S4), probably because CHCA is a "hot matrix"12 and $\left[\mathrm{V}^{2+}+\mathrm{PF}_{6}^{-}\right]^{+}$cannot survive in MALDI under these experimental conditions. Although $\mathrm{V}^{2+}$ is doubly charged, it is readily reduced to a singly charged cation radical $\left[\mathrm{V}^{2+}+\mathrm{e}\right]^{+}$through capture of a single electron owing to the highly electron-deficient core. ${ }^{33}$ At

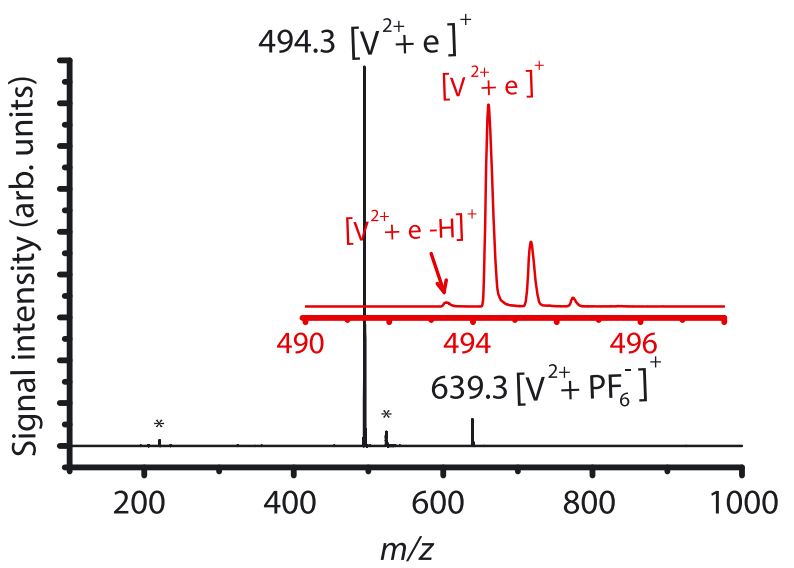

FIGURE 3 The matrix-assisted laser desorption/ionization time-offlight mass spectrometry of $\mathrm{V}\left(\mathrm{PF}_{6}\right)_{2}$ using 2-[(2E)-3-(4-tertbutylphenyl)-2-methylprop-2-enylidene] malononitril (DCTB) as the matrix. The molecular structure of $\mathrm{V}\left(\mathrm{PF}_{6}\right)_{2}$ is given in Figure 1 $\left(\mathrm{V}^{2+}=\mathrm{C}_{30} \mathrm{H}_{42} \mathrm{~N}_{2} \mathrm{O}_{4}{ }^{2+}\right) .{ }^{*}$ indicates matrix peaks. DCTB is dissolved in

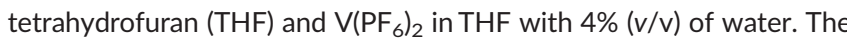
mole ratio of $\mathrm{V}\left(\mathrm{PF}_{6}\right)_{2} / \mathrm{DCTB}$ is 1:100 [Colour figure can be viewed at wileyonlinelibrary.com]

first glance, it would appear as if $\mathrm{V}^{2+}$ is reduced by simple one-electron reduction, in a similar way to multiply charged metal ions. However, the actual mechanisms for charge reduction of multivalent metal ions and of multivalent organic ions are very much different. For a multivalent metal ion, the charges are confined to one-metal atom. By contrast, the 2 charges of a viologen core are shared among several atoms of the 2 pyridine rings via $\pi$-conjugation. On electron capture, the viologen core rearranges as shown in Scheme 2.33,34 Depending 


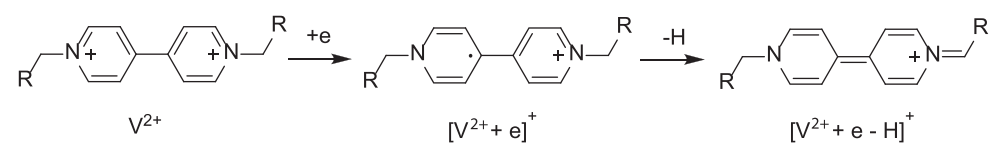

SCHEME 2 A scheme for the formation of $\left[\mathrm{V}^{2+}+\mathrm{e}\right]^{+}$and $\left[\mathrm{V}^{2+}+\mathrm{e}-\mathrm{H}\right]^{+}$

on the experimental conditions, the odd-electron radical ion of $\left[\mathrm{V}^{2+}+\mathrm{e}\right]^{+}$can further lose one $\mathrm{H}$ forming $\left[\mathrm{V}^{2+}+\mathrm{e}-\mathrm{H}\right]^{+}$. A small but clear peak of the $\left[\mathrm{V}^{2+}+\mathrm{e}-\mathrm{H}\right]^{+}$fragment was observed with either DCTB (see the red inset of Figure 3 ) or CHCA matrix (ESI, Figure S4).

The MALDI TOF MS spectrum of $B V\left(\mathrm{PF}_{6}\right)_{4}$ using DCTB as the matrix is shown in Figure 4. $\mathrm{BV}^{4+}$ has 2 highly electron-deficient dicationic cores of viologen. With DCTB matrix, 4 pseudo-molecular ion peaks with mass difference of 145 Dalton were observed which can easily be assigned to $\mathrm{BV}^{4+}$ ions with different numbers of $\left(\mathrm{PF}_{6}\right)^{-}$counter ions. However, no peaks of $\left[\mathrm{BV}^{4+}+3\left(\mathrm{PF}_{6}\right)^{-}\right]^{+}$and only tiny peaks of $\left[\mathrm{BV}^{4+}+\mathrm{e}+2\left(\mathrm{PF}_{6}\right)^{-}\right]^{+}$were observed with $\mathrm{CHCA}$ matrix (ESI, Figure S5). Once again, the absence of $\left[\mathrm{BV}^{4+}+3\left(\mathrm{PF}_{6}\right)^{-}\right]^{+}$is probably because of the use of the hot CHCA matrix, which disfavors its survival. In forming the singly charged ions, different numbers of electrons must be involved for charge reduction. After electron capture, the viologen cores might further rearrange and/or fragment. As in Scheme 2 for $\mathrm{V}^{2+}$, fragment ions resulted from the loss of different numbers of $\mathrm{H}$ radical could also be expected. The possible routes of rearrangement and $\mathrm{H}$ radical dissociation for $\mathrm{BV}^{4+}$ after catching electrons are illustrated in the ESI (see Scheme S3). Indeed, fragment ions formed through the loss of $\mathrm{H}$ radicals, such as $\left[\mathrm{BV}^{4+}+\mathrm{e}+2\left(\mathrm{PF}_{6}\right)^{-}-\mathrm{H}\right]^{+},\left[\mathrm{BV}^{4+}+2 \mathrm{e}+\left(\mathrm{PF}_{6}\right)^{-}-\mathrm{H}\right]^{+}$,
$\left[\mathrm{BV}^{4+}+2 \mathrm{e}+\left(\mathrm{PF}_{6}\right)^{-}-2 \mathrm{H}\right]^{+},\left[\mathrm{BV}^{4+}+3 e-\mathrm{H}\right]^{+}$and $\left[\mathrm{BV}^{4+}+3 e-2 \mathrm{H}\right]^{+}$, were observed (see insets of Figure 4).

Additional supporting evidence for charge reduction by electron capture instead of by loss of protons can be found by analyzing the cluster of ions at $\mathrm{m} / \mathrm{z}$ around 692. If the charge reduction is to be achieved by loss of protons, then the loss of 3 protons is required for $\mathrm{BV}^{4+}$ to form a singly charged ion. However, we could not detect $\left[\mathrm{BV}^{4+}-3 \mathrm{H}^{+}\right]$ ${ }^{+}$ions (see Figures 4 and $\mathrm{S} 5$ ). The lack of $\left[\mathrm{BV}^{4+}-3 \mathrm{H}^{+}\right]^{+}$and the observation of $\left[\mathrm{BV}^{4+}+3 e\right]^{+},\left[\mathrm{BV}^{4+}+3 e-\mathrm{H}\right]^{+}$and $\left[\mathrm{BV}^{4+}+3 e-2 \mathrm{H}\right]^{+}$ions strongly support the mechanisms proposed above for the charge reduction and fragmentation for viologen derivatives.

Our results also reveal that mechanisms other than electron capture exist to reduce the multiple charges of $\mathrm{BV}^{4+}$. In addition to the pseudo-molecular ions and the fragments discussed above, a number of other fragment ions were also clearly observed in Figure 4. The formation of these fragments can be attributed to the cleavage of the linkage between the two doubly charged bipyridiunm cores. Considering the quadruple charges and the small molecular size of $\mathrm{BV}^{4+}$, the charge repulsion within the ion must be significant. Because of the charge repulsion, the most fragile bond within the $\mathrm{BV}^{4+}$ ion should be the aliphatic chain between the 2 bipyridiunm cores. A schematic diagram of possible pathways for the cleavage is given in Scheme 3.

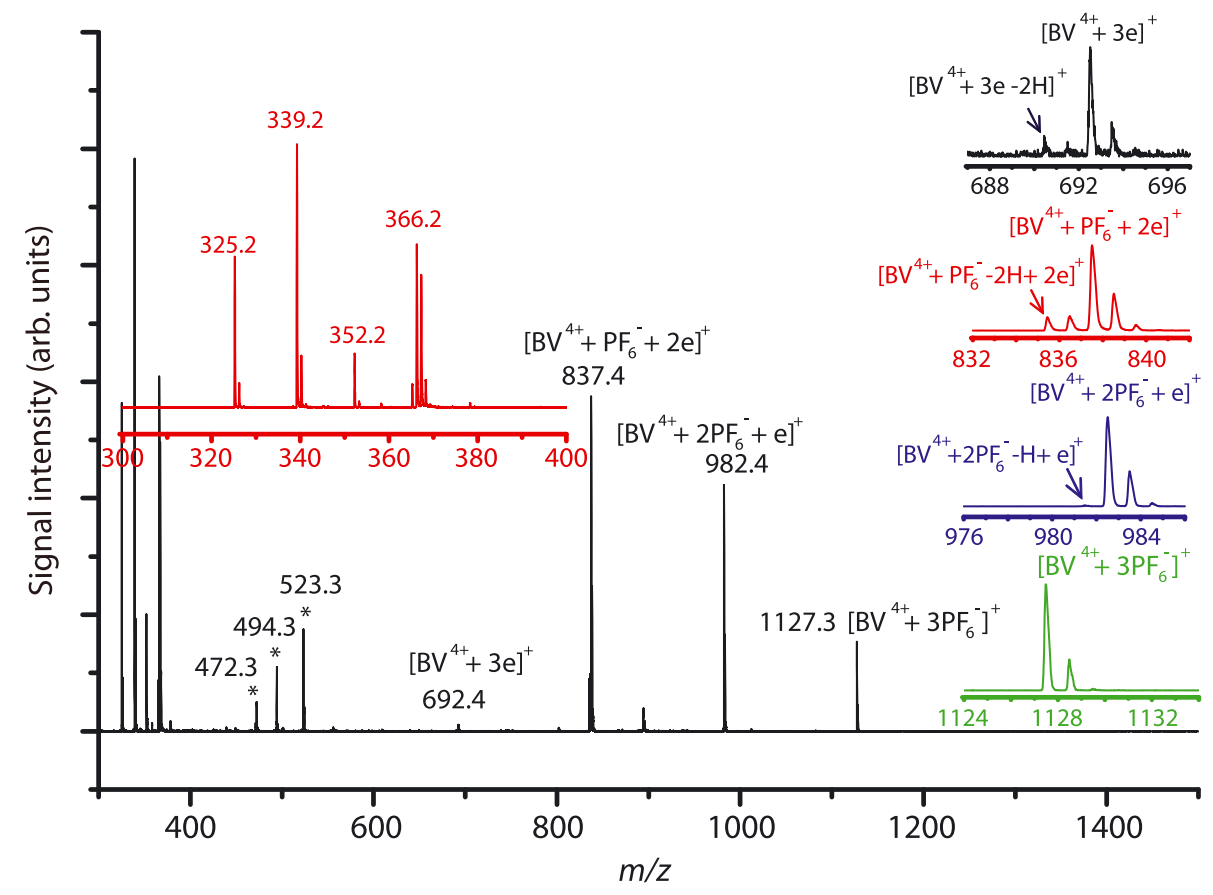

FIGURE 4 The matrix-assisted laser desorption/ionization time-of-flight mass spectrometry of $\mathrm{BV}\left(\mathrm{PF}_{6}\right)_{4}$ using 2-[(2E)-3-(4-tert-butylphenyl)-2methylprop-2-enylidene] malononitril (DCTB) as the matrix. The molecular structure of $B V\left(\mathrm{PF}_{6}\right)_{4}$ is given in Figure $1\left(\mathrm{BV}^{4+}=\mathrm{C}_{43} \mathrm{H}_{56} \mathrm{~N}_{4} \mathrm{O}_{4}{ }^{4+}\right)$. The assignment of the fragment ions in the $\mathrm{m} / \mathrm{z}$ range between 300 and 400 is shown in Scheme $3 .{ }^{*}$ the peak of $\mathrm{m} / \mathrm{z}$ at 523.3 is a matrix peak; the peak of $\mathrm{m} / \mathrm{z}$ at 494.3 is a peak of $\left[\mathrm{V}^{2+}+\mathrm{e}\right]^{+}$(see Figure 2); and the peak of $\mathrm{m} / \mathrm{z}$ at 472.3 could not be assigned. DCTB is dissolved in tetrahydrofuran $(\mathrm{THF})$ and $\mathrm{BV}\left(\mathrm{PF}_{6}\right)_{4}$ in THF with $4 \%(\mathrm{v} / \mathrm{v})$ of water. The molar ratio of $\mathrm{BV}\left(\mathrm{PF}_{6}\right)_{4} / \mathrm{DCTB}$ is $1: 100$ 


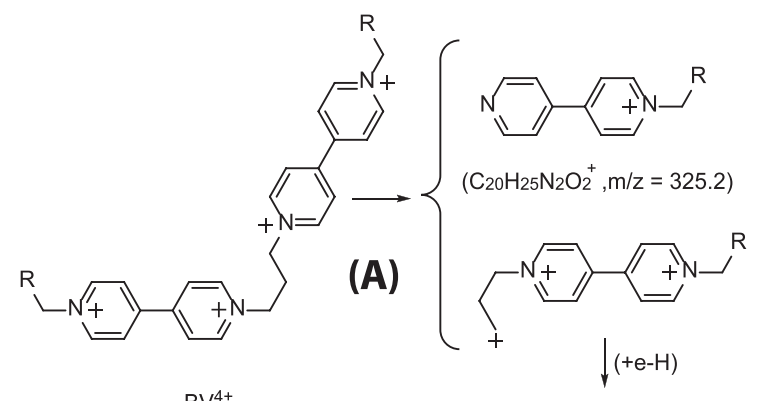

$\mathrm{BV}^{4+}$<smiles>[R]C[n+]1ccc(-c2cc[n+](CC=C)cc2)cc1</smiles>

$(+e)$

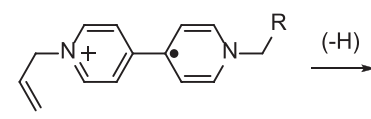

$\left(\mathrm{C}_{23} \mathrm{H}_{30} \mathrm{~N}_{2} \mathrm{O}_{2}{ }^{+}, \mathrm{m} / \mathrm{z}=366.2\right)$

$\rightarrow$ $(+e)$

$\left(\mathrm{C}_{23} \mathrm{H}_{31} \mathrm{~N}_{2} \mathrm{O}_{2}{ }^{+}, \mathrm{m} / \mathrm{z}=367.2\right)$
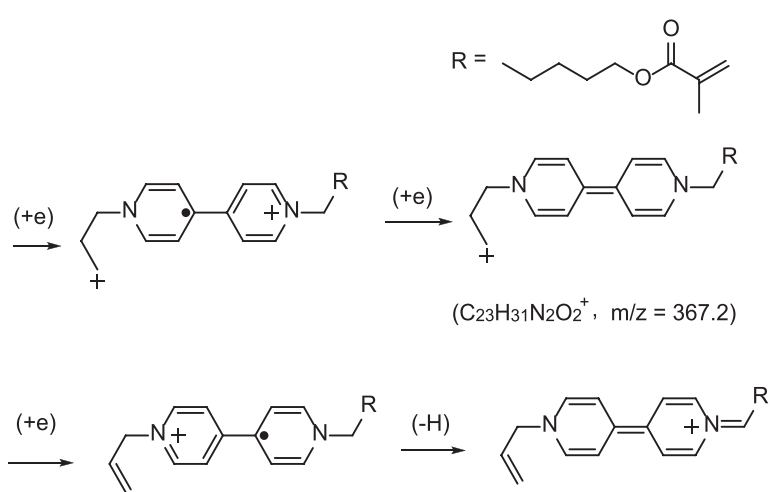

$\left(\mathrm{C}_{23} \mathrm{H}_{29} \mathrm{~N}_{2} \mathrm{O}_{2}{ }^{+}, \mathrm{m} / \mathrm{z}=365.2\right)$

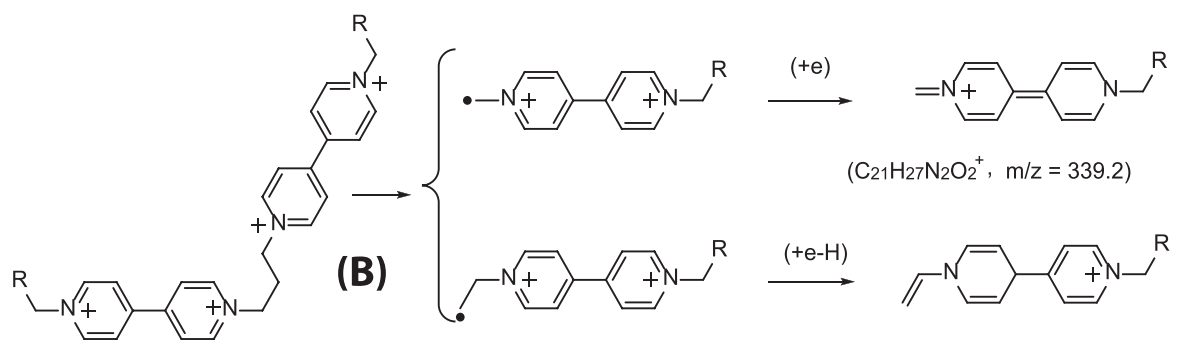

$\left(\mathrm{C}_{22} \mathrm{H}_{28} \mathrm{~N}_{2} \mathrm{O}_{2}^{+}, \mathrm{m} / \mathrm{z}=352.2\right)$

$\mathrm{BV}^{4+}$

SCHEME 3 Schemes for the fragmentation of $\mathrm{BV}^{4+}$ by cleavage of the alkyl chain between the two doubly charged viologen groups. (A) Cleavage of a $\mathrm{C}-\mathrm{N}^{+}$bond and (B) cleavage of a $\mathrm{C}-\mathrm{C}$ bond

Compellingly, all the predicted fragment ions were observed with both DCTB and CHCA matrices (Figures 4 and S5).

\section{3 | Cyanine dye-labelled BTA derivatives}

Benzene-1,3,5-tricarboxamide (BTA) derivatives can self-assemble into supramolecular polymers via reversible intermolecular hydrogen bonding and $\pi-\pi$ stacking, which together with a variety of secondary interactions, is used to make novel supramolecular materials. ${ }^{35}$ Recently, 2 cyanine dyes (Cy3 and Cy5) were used as fluorescent labels to study the spatiotemporal control and selectivity in supramolecular polymers. ${ }^{24,25}$ In this work, 2 BTA derivatives with 2 and 3 Cy 5 attached as dye labels, (BTA2Cy5) $\mathrm{Cl}_{2}$ and (BTA3Cy5) $\mathrm{Cl}_{3}$, were measured by MALDI TOF MS. The structures of the derivatives are provided in Figure 1.

The MALDI TOF MS spectra of (BTA2Cy5) $\mathrm{Cl}_{2}$ and (BTA3Cy5) $\mathrm{Cl}_{3}$ using CHCA matrix are shown in Figure 5. Similar results were also obtained using DCTB as matrix. Since one Cy5 bears one positive charge, the number of fixed charges is determined by the number of Cy5 attached in the BTA derivative. Based on the $m / z$ values, the most abundant ion peaks can be assigned as $\left[\mathrm{BTA} 2 \mathrm{Cy} 5^{2+}-\mathrm{H}^{+}\right]^{+}$and $\left[\mathrm{BTA} 3 \mathrm{Cy} 5^{3+}-2 \mathrm{H}^{+}\right]^{+}$for $(\mathrm{BTA2Cy} 5) \mathrm{Cl}_{2}$ and $(\mathrm{BTA} 3 \mathrm{Cy} 5) \mathrm{Cl}_{3}$, respectively. Judging on these data, it would appear that these ions form through loss of protons.

From Figure 5, it can also be seen clearly that deprotonation is not the only mechanism by which these 2 BTA compounds undergo charge reduction. Fragment peaks of $\left[\mathrm{BTA} 2 \mathrm{Cy} 5^{2+}-\mathrm{CH}_{3}{ }^{+}\right]^{+}$, $\left[\mathrm{BTA} 3 \mathrm{Cy} 5^{3+}-\mathrm{H}^{+}-\mathrm{CH}_{3}{ }^{+}\right]^{+}$, and $\left[\mathrm{BTA} 3 \mathrm{Cy} 5^{3+}-2 \mathrm{CH}_{3}{ }^{+}\right]^{+}$were also

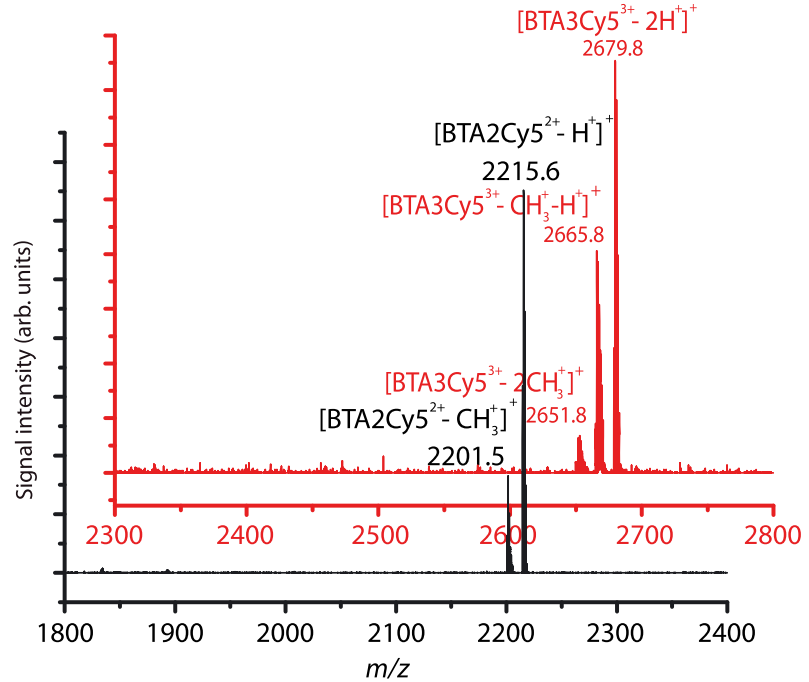

FIGURE 5 Matrix-assisted laser desorption/ionization time-of-flight mass spectrometry of BTA2 $\mathrm{Cy} 5 \mathrm{Cl}_{2}$ (spectrum in black) and BTA3Cy $5 \mathrm{Cl}_{3}$ (spectrum in red) using a-cyano-4-hydrocycinnamic acid ( $\mathrm{CHCA}$ ) as the matrix. The molecular structures of the analytes are given in Figure 1 (BTA2Cy5 $5^{2+}=\mathrm{C}_{133} \mathrm{H}_{206} \mathrm{~N}_{10} \mathrm{O}_{17}{ }^{2+}$ and BTA3Cy $\left.5^{3+}=\mathrm{C}_{165} \mathrm{H}_{243} \mathrm{~N}_{12} \mathrm{O}_{18}{ }^{3+}\right)$. CHCA is dissolved in tetrahydrofuran and analytes in methanol. The mole ratio of analyte/ CHCA for both samples is 1:100 [Colour figure can be viewed at wileyonlinelibrary.com]

observed for (BTA2Cy5) $\mathrm{Cl}_{2}$ and (BTA3Cy5) $\mathrm{Cl}_{3}$, respectively. Considering the chemical structure of $\mathrm{Cy}^{+}$, the methyl groups on the $\mathrm{C}$ atoms close to the benzene rings would appear to be easily cleaved as doing 
$\mathrm{R}^{2} \mathrm{HN}\left(\mathrm{H}_{2} \mathrm{CH}_{2} \mathrm{CO}\right)_{4}\left(\mathrm{H}_{2} \mathrm{C}\right)_{12} \mathrm{HN}$

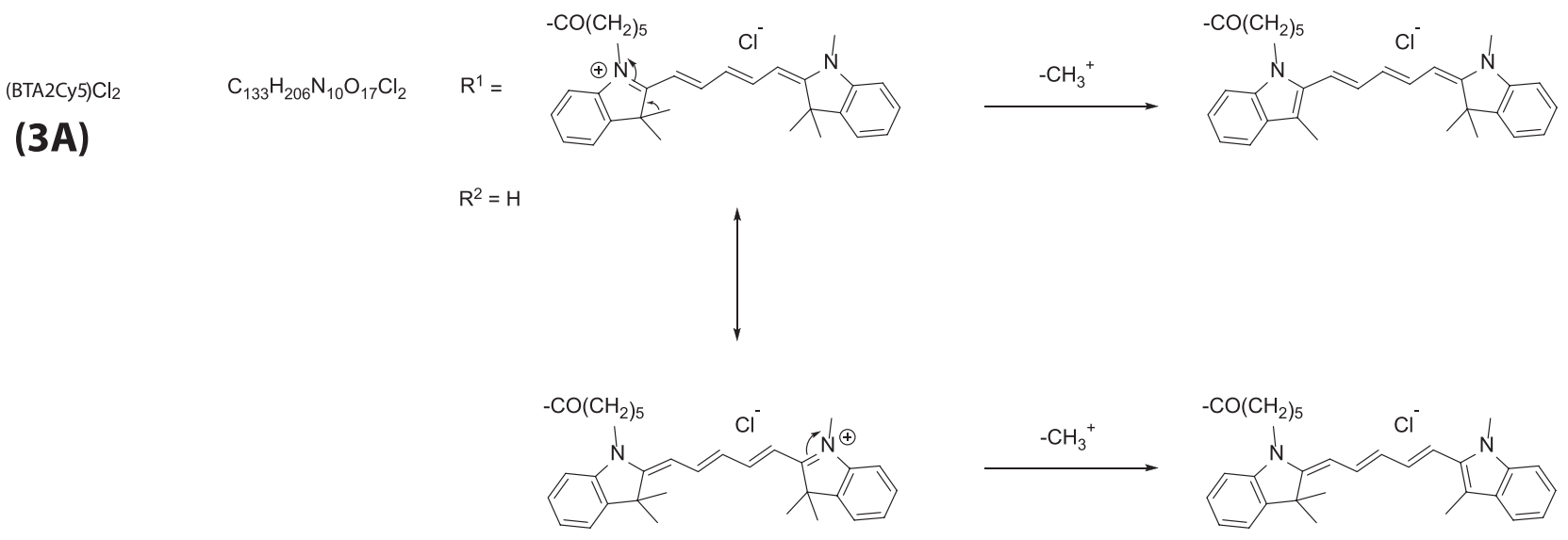

SCHEME 4 Schemes for charge reduction of BTA2Cy $5^{2+}$

so would not interfere with the $\pi$-conjugation through the dye moiety. Scheme 4 shows the possible pathways for charge reduction of BTA2Cy $5^{2+}$. Obviously, for BTA3Cy $5^{3+}$, cleaving off $2 \mathrm{CH}_{3}$ groups from 2 different $\mathrm{Cy} 5 \mathrm{~s}$ is required for the formation of a singly charged ion.

\section{4 | Perylene bisimide derivative}

Perylene bisimide derivatives are an important class of dyes useful for textile applications and as additives in high-grade industrial paint. ${ }^{36,37}$ As perylene bisimides feature a relatively low reduction potential which enables their use as an n-type semiconductor and as an electron acceptor in photoiduced charge transfer reactions, they have also been widely used in various optical and optoelectronical applications. ${ }^{38,39}$ In this study, a quaternized ammonium perylene bisimide (QPB) was measured using MALDI TOF MS, of which the structure is given in Figure 1.

Figure 6 shows the MALDI TOF MS spectra of QPB. Like Qdenr1, QPB is also doubly charged, bearing 2 quarternized ammonium centers. The peaks at $\mathrm{m} / \mathrm{z}$ of 831.5 and 786.4 , which were observed using both CHCA and DCTB as matrices, can be assigned as $\left[\mathrm{QPB}^{2+}-\mathrm{CH}_{3}^{+}\right]^{+}$and $\left[\mathrm{QPB}^{2+}-\mathrm{N}\left(\mathrm{CH}_{3}\right)_{3}-\mathrm{H}^{+}\right]^{+}$, respectively. As discussed above for Qdendr1, charge reduction for a quarternized ammonium can be achieved through cleavage across 1 of the $4 \mathrm{~N}-\mathrm{C}$ bonds. A schematic diagram of fragmentation pathways for QPB is provided in Scheme 5, which is similar to that for Qdendr1 (Scheme 1).

Interestingly, QPB also consists of a highly electron-deficient perylene group. Owing to the electron deficient nature of the perylene group, an electron could easily be captured and stabilized within the $\pi$-conjugated system of perylene. It is known for similar electron deficient groups, a singly charged ion such as $\left[\mathrm{M}+2 \mathrm{Na}^{+}+\mathrm{e}\right]^{+}$can be formed through double cation adduction combined with electron capture. ${ }^{40}$ Although not detected when using CHCA as matrix (the red spectrum of Figure 6 ), an intense singly charged molecular ion peak $\left[\mathrm{QPB}^{2+}+\mathrm{e}\right]^{+}$of $m / z$ at 846.5 , formed by one electron reduction, was clearly observed for QPB with DCTB as the matrix (the black spectrum of Figure 6).

\section{5 | Tetrathiafulvalene as matrix}

In the experiments discussed above, 2 popular MALDI matrices of CHCA and DCTB were studied. Asakawa et al reported the use of tetrathiafulvalene (TTF), an electron donating compound, as a matrix for the analysis of some industrial pigments. ${ }^{41}$ Inspired by their nice results, we also tested TTF for the analytes containing ions bearing fixed multiple charges. Under our conditions, no analyte ions were detected for (QDendr1) $\mathrm{I}_{2}$, (BTA2Cy5) $\mathrm{Cl}_{2}$, and (BTA3CY5) $\mathrm{Cl}_{3}$, indicating that TTF is not a good matrix for these compounds. The MALDI TOF MS spectra for $\mathrm{V}\left(\mathrm{PF}_{6}\right)_{2}, \mathrm{BV}\left(\mathrm{PF}_{6}\right)_{4}$, and $(\mathrm{QPB}) \mathrm{Br}_{2}$ are given in the $\mathrm{ESI}$ (Figures S6-S8), which are similar to the corresponding spectra obtained with CHCA and DCTB matrices. Apparently, the strong

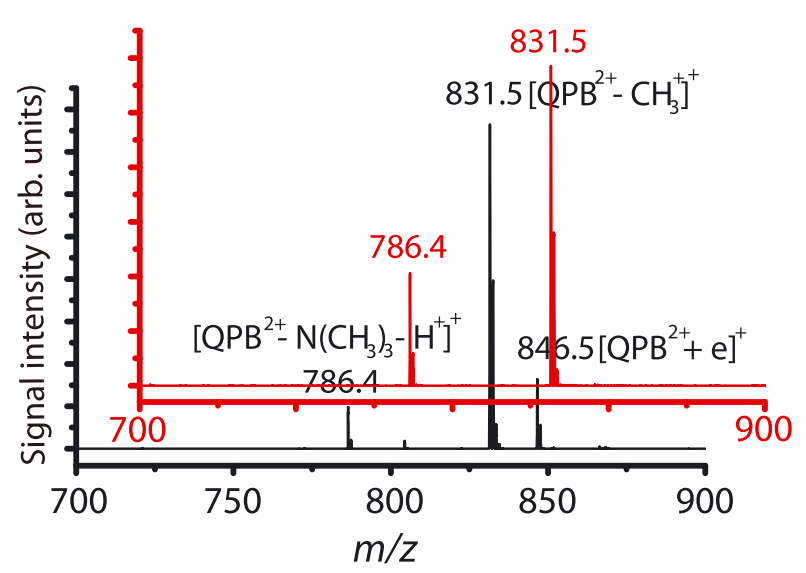

FIGURE 6 Matrix-assisted laser desorption/ionization time-of-flight mass spectrometry of (QPB) $\mathrm{Br}_{2}$ using a-cyano-4-hydrocycinnamic acid (CHCA) (spectrum in red) and 2-[(2E)-3-(4-tert-butylphenyl)-2methylprop-2-enylidene] malononitril (DCTB) (spectrum in black) as the matrices. The molecular structure of the analyte is given in Figure 1 $\left(\mathrm{QPB}^{2+}=\mathrm{C}_{133} \mathrm{H}_{206} \mathrm{~N}_{10} \mathrm{O}_{17}{ }^{2+}\right)$. CHCA and DCTB are dissolved in tetrahydrofuran and (QPB) $\mathrm{Br}_{2}$ in THF with $2 \%$ dimethyl sulfoxide. The mole ratio of analyte/matrix for both matrices is 1:100 [Colour figure can be viewed at wileyonlinelibrary.com] 


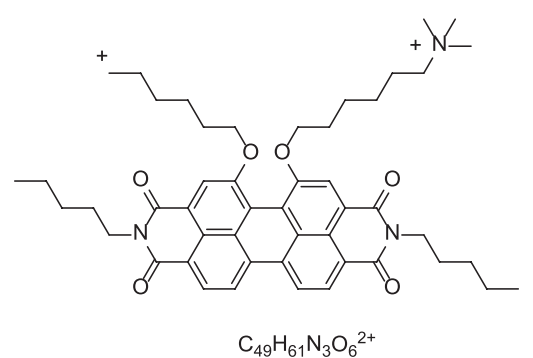

$\mathrm{C}_{49} \mathrm{H}_{61} \mathrm{~N}_{3} \mathrm{O}_{6}{ }^{2+}$

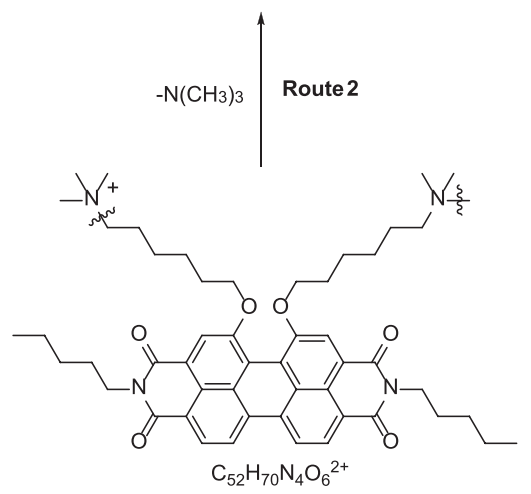

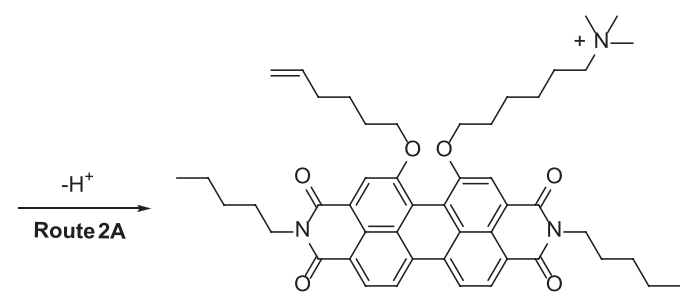

$\mathrm{C}_{49} \mathrm{H}_{60} \mathrm{~N}_{3} \mathrm{O}_{6}{ }^{+}, \mathrm{m} / \mathrm{z}=786.4$

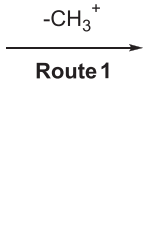

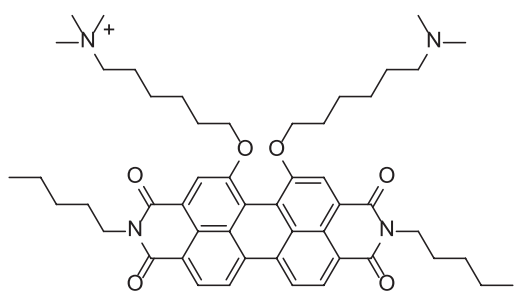

$\mathrm{C}_{51} \mathrm{H}_{67} \mathrm{~N}_{4} \mathrm{O}_{6}^{+}, \mathrm{m} / \mathrm{z}=831.5$

SCHEME 5 Schemes for charge reduction of $\mathrm{QPB}^{2+}$

electron donating property of TTF did not yield considerably more reduced analyte molecular ions via electron capture. The reason for this observation is still under investigation.

It is well known that MALDI MS results are strongly matrix dependent. Although noticeable differences were observed in the mass spectra using different matrices, all the ions recorded in the spectra are singly charged because of the strong tendency to form singly charged ions in MALDI. For multiply charged organic ions, the fixed charges are not confined to one atom, which is in clear contrast with multivalent metal ions. Upon electron capture, fragmentation will occur concurrently for the organic ions. In addition, reduction via charge splitting is also an important route for the formation of singly charged fragment ions. Because of the fragmentation reactions, extra care should be taken in the MALDI MS analysis of organic ions bearing fixed multiple charges.

\section{4 | CONCLUSIONS}

A series of fragment ion peaks were observed in the MALDI TOF MS analysis of organic ions bearing fixed multiple charges. Although all of the organic ions studied in this work are intrinsically multiply charged, only singly charged ions were observed. In addition to counterion adduction, deprotonation, and electron capture, fragmentation was also found to be an important route for charge reduction. Cleavage of a chemical bond to the charged centers and/or rearrangement of the ions after catching electron(s) are found to be the main possible pathways of fragmentation. Therefore, care should be taken when interpreting MALDI MS data measured on ions bearing fixed multiple charges. With an improved understanding of the possible fragmentation mechanisms, MALDI TOF MS should still be a very useful technique for the characterization of organic ions bearing fixed multiple charges.

\section{ACKNOWLEDGEMENTS}

The authors would like to thank Dr J.A.J.M Vekemans and Dr K. Pieterse for valuable discussions and constructive suggestions.

\section{ORCID}

Xianwen Lou (10 http://orcid.org/0000-0002-5403-3647

\section{REFERENCES}

1. Hillenkamp F, Peter-Katalinić J (Eds). MALDI MS: A Practical Guide to Instrumentation, Method and Applications. Weinheim: Wiley- $\mathrm{VCH}$; 2007.

2. Cole RB (Ed). Electrospray and MALDI Mass Spectrometry. Fundamentals, Instrumentation, Practicalities, and Biological Applications. 2nd ed. Hoboken: Wiley; 2010.

3. Cai Z, Liu S (Eds). Applications of MALDI TOF Spectrometry. Berlin: Springer-Verlag; 2013.

4. Karas M, Glückmann M, Schäfer J. Ionization in matrix-assisted laser desorption/ionization: singly charged molecular ions are the lucky survivors. J Mass Spectrom. 2000;35:1-12.

5. Karas M, Krüger R. Ion formation in MALDI: the cluster ionization mechanism. Chem Rev. 2003;103:427-440.

6. Krüger R, Pfenninger A, Fournier I, Glückmann M, Karas M. Analyte incorporation and ionization in matrix-assisted laser desorption/ionization visualized by $\mathrm{pH}$ indicator molecular probes. Anal Chem. 2001;73:5812-5821

7. Trimpin S, Inutan ED. Matrix assisted ionization in vacuum, a sensitive and widely applicable ionization method for mass spectrometry. J Am Soc Mass Spectrom. 2013;24:722-732.

8. Trimpin S. A perspective on MALDI alternatives-total solvent-free analysis and electron transfer dissociation of highly charged ions by laserspray ionization. J Mass Spectrom. 2010;45:471-485. 
9. Cramer R, Pirkl A, Hillenkamp F, Dreisewerd K. Liquid AP-UV-MALD enables stable ion yields of multiply charged peptide and protein ions for sensitive analysis by mass spectrometry. Angew Chem Int Ed. 2013;52:2364-2367.

10. Frankevich V, Zhang J, Dashtiev M, Zenobi R. Production and fragmentation of multiply charged ions in 'electron-free' matrix-assisted laser desorption/ionization. Rapid Commun Mass Spectrom. 2003;17: 2343-2348.

11. Ehring $\mathrm{H}$, Karas M, Hillenkamp F. Role of photoionization and photochemistry in ionization processes of organic molecules and relevance for matrix-assisted laser desorption ionization mass spectrometry. Organic Mass Spectrom. 1992;27:472-480.

12. Zenobi R, Knochenmuss R. Ion formation in MALDI mass spectrometry. Mass Spectrom Rev. 1998;17:337-366.

13. Knochenmuss R, Zenobi R. MALDI lonization: the role of in-plume processes. Chem Rev. 2003;103:441-452.

14. Trimpin S, Wang B, Inutan ED, et al. A mechanism for ionization of nonvolatile compounds in mass spectrometry: considerations from MALDI and inlet ionization. J Am Soc Mass Spectrom. 2012;23:1644-1660.

15. Dreisewerd K. The desorption process in MALDI. Chem Rev. 2003; 103:395-425.

16. Jaskolla TW, Karas M. Compelling evidence for lucky survivor and gas phase protonation. J Am Soc Mass Spectrom. 2011;22:976-988.

17. Zhang J, Frankevich V, Knochenmuss R, Friess SD, Zenobi R. Reduction of $\mathrm{Cu}(\mathrm{II})$ in matrix-assisted laser desorption/ionization mass spectrometry. J Am Soc Mass Spectrom. 2003;14:42-50.

18. Rashidezadeh H, Guo B. Investigation of metal attachment to polystyrenes in matrix-assisted laser desorption ionization. J Am Soc Mass Spectrom. 1998;9:724-730.

19. Woods AS, Buchsbaum JC, Worrall TA, Berg JM, Cotter RJ. Matrixassisted laser desorption/ionization of noncovalently bound compounds. Anal Chem. 1995;67:4462-4465.

20. Wong CKL, Chan TWD. Cationization processes in matrix-assisted laser desorption/ionization mass spectrometry: attachment of divalent and trivalent metal ions. Rapid Commun Mass Spectrom. 1997;11:513-519.

21. Schäfer M, Budzikiewicz $H$. A fast atom bombardment and matrixassisted laser desorption/ionization mass spectrometry study of doubly charged porphyrins. J Mass Spectrom. 2001;36:1062-1068.

22. Meier MAR, Lohmeijer BGG, Schubert US. Relative binding strength of terpyridine model complexes under matrix-assisted laser desorption/ ionization mass spectrometry conditions. J Mass Spectrom. 2003; 38:510-516.

23. Tack F, Bakker A, Maes S, et al. Modified poly(propylene imine) dendrimers as effective transfection agents for catalytic DNA enzymes (DNAzymes). J Drug Target. 2006;14:69-86.

24. Albertazzi L, van der Zwaag D, Leenders CMA, Fitzner R, van der Hofstad RW, Meijer EW. Probing exchange pathways in onedimensional aggregates with super-resolution microscopy. Science. 2014;344:491-495.

25. Albertazzi L, Martinez-Veracoechea FJ, Leenders CMA, Voets IK, Frenkel D, Meijer EW. Spatiotemporal control and superselectivity in supramolecular polymers using multivalency. Proc Natl Acad Sci U S A. 2013;110:12203-12208.

26. Ulmer L, Mattay J, Torres-Garcia HG, Luftmann H. The use of 2-[(2E)-3(4-tert-butylphenyl)-2-methylprop-2-enylidene]malononitrile as a matrix for matrix-assisted laser desorption/ionization mass spectrometry. Eur J Mass Spectrom. 2000;6:49-52.
27. Lou X, Dongen JLJ, Meijer EW. Generation of CsI cluster ions for mass calibration in matrix-assisted laser desorption/ionization mass spectrometry. J Am Soc Mass Spectrom. 2010;21:1223-1226.

28. Hummelen JC, van Dongen JLJ, Meijer EW. Electrospray mass spectrometry of poly(propylene imine) dendrimers-the issue of dendritic purity or polydispersity. Chem - A Eur Journal. 1997;3:1489-1493.

29. Weener JW, van Dongen JLJ, Meijer EW. Electrospray mass spectrometry studies of poly(propylene imine) dendrimers: probing reactivity in the gas phase. J Am Chem Soc. 1999;121:10346-10355.

30. Cooper HJ, Hakansson K, Marshall AG. The role of electron capture dissociation in biomolecular analysis. Mass Spectrom Rev. 2005;24: 201-222.

31. Grayson SK, Fréchet JMJ. Convergent dendrons and dendrimers: from synthesis to applications. Chem Rev. 2001;101:3819-3868.

32. Monk PMS. The Viologens: Physicochemical properties, synthesis and applications of the salts of 4,4'-bipyridine. New York: Wiley; 1998.

33. Porter WW, Vaid TP, Rheingold AL. Synthesis and characterization of a highly reducing neutral "extended viologen" and the isostructural hydrocarbon 4,4"-di-n-octyl-p-quaterphenyl. J Am Chem Soc. 2005;127: 16559-16566.

34. Lou X, Spiering AJH, de Waal BFM, van Dongen JLJ, Vekemans JAJM, Meijer EW. Dehydrogenation of tertiary amines in matrix-assisted laser desorption/ionization time-of-flight mass spectrometry. J Mass Spectrom. 2008;43:1110-1122.

35. Leenders CMA, Albertazzi L, Mes T, Koenigs MM, Palmans AR, Meijer EW. Supramolecular polymerization in water harnessing both hydrophobic effects and hydrogen bond formation. Chem Commun. 2013;49:1963-1965.

36. Herbst W, Hunger K, Wilker G, Ohleier H, Winter R. Ind. Org. Pigments. Weinheim: Wiley-VCH Verlag GmbH \& Co. KGaA; 2004.

37. Weil T, Vosch T, Hofkens J, Peneva K, Müllen K. The rylene colorant family--tailored nanoemitters for photonics research and applications. Angew Chem Int Ed. 2010;49:9068-9093.

38. Zhan X, Facchetti A, Barlow S, et al. Rylene and related diimides for organic electronics. Adv Mater. 2011;23:268-284.

39. Liu Z, Zhang G, Cai Z, et al. New organic semiconductors with imide/ amide-containing molecular systems. Adv Mater. 2014;26:6965-6977.

40. Lou X, Sinkeldam RW, van Houts W, et al. Double cation adduction in matrix-assisted laser desorption/ionization time-of-flight mass spectrometry of electron deficient anthraquinone derivatives. J Mass Spectrom. 2007;42:293-303.

41. Asakawa D, Chen LC, Hiraoka K. Negative-mode MALDI mass spectrometry for the analysis of pigments using tetrathiafulvalene as a matrix. J Mass Spectrom. 2008;43:1494-1501.

\section{SUPPORTING INFORMATION}

Additional Supporting Information may be found online in the supporting information tab for this article.

How to cite this article: Lou X, Li B, de Waal BFM, et al. Fragmentation of organic ions bearing fixed multiple charges observed in MALDI MS. J Mass Spectrom. 2018;39-47. https://doi.org/10.1002/jms.4035 